\title{
DZIGA VERTOV AND STEVE MANN: The Embodiment of the Master Metaphor of Vision
}

By Angela Joosse

\begin{abstract}
$\mathrm{A}^{\mathrm{t}}$ the intersection of technology and culture, the master meta1 phor of vision maintains a prominent position. The privileged status of sight in Western culture can be understood as part of the striving to see the world more clearly, to combat distortion and gain an "objective" view. At the turn of the century, new imaging technologies were put into practice as a part of a utopic hope for the future and the modernist project to dispel myth. At the turn of the new millennium, the ubiquitous presence of technologies comprises a controlling system against which we must renew our vision once again. In both contexts, the use of imaging technologies offer liberating possibilities by bringing attention to controlling devices which conspire to remain hidden. Further, theoretical inquiry into the study of technology and culture is often concerned with questions of vision, and approaches are often articulated through metaphors of vision. Within this framework, the writing and practice of both Dziga Vertov (1896-1954) and Steve Mann (1962_) can be studied as embodied approaches to the meeting place of theory, technology and culture. ${ }^{1}$
\end{abstract}

This paper will make use of Paula Saukko's approach of "combining methodologies" as described in her book Doing Research in Cultural Studies (2003). Here, Saukko discusses the evaluation of cultural research in terms of "validities," which circumvents any attempt at a universal rule or truth, but still provides grounds for rigorous assessment of cultural research (Saukko 19). The "combining methodologies" approach incorporates the three disparate, and

1 The author's understanding of Vertov has been informed by the research and lectures of R. Bruce Elder. 
often incongruent, major methodological approaches in Cultural Studies. Combined are dialogic validity, which evaluates the research according to how well it expresses the lived realities of others; contextual validity, which assesses the relationship of the research to social and historical contexts; and deconstructive validity, which evaluates the ability of the research to unravel taken-for-granted social discourses. In this paper, these three different validities will be used to assess two written expressions of embodied experiences through imaging technology: Dziga Vertov's "Kinoks: A Revolution" (1922) and Steve Mann's introduction to his book Cyborg (2001). Even though the works of Vertov and Mann can not be strictly categorized as cultural research, they can be understood as extensions of a bias towards visual metaphors in cultural theory, as well as part of the methodological practice of using a carefully constructed apparatus in order to see the world more clearly.

Generally, I understand Vertov's and Mann's work to be lived expressions of the ocularcentrism in Western culture that is also prominent in the theorizing of technology and culture. Within the development of Western philosophy and science, vision gained the status of being the most reliable and noble sense, and so discussions around vision also carry a great deal of symbolic weight. ${ }^{2}$ Indeed, even though current cultural theory has given up on the possibility of an objective perspective, language in the West remains biased toward the sense of sight and our philosophical tradition emphasises the desire to see the world more clearly. Metaphors of vision dominate, from Foucault's description of the omnipotent surveillance of the panopticon (Foucault 201), to Virilio's argument that new technologies are constantly accelerating human experience to the point where vision is reduced to a blur at the speed of light (Virilio 41), to Haraway's methodological approach of diffraction (Haraway, Promises of Monsters 300). Ironically, even as Saukko tries to propose a sound-based methodology as an alternate to those based

2 For a comprehensive study of ocularcentrism in Western culture, see Downcast Eyes (1993) by Martin Jay. 
on vision her language remains rooted in the visual: "To illustrate what a sound-based or dialogic approach to combining methodologies would look like, I will sketch a possible way of analyzing" (31, emphasis added). The struggle to see, and the power to see continues to hold a central place at the intersection of theory, culture, and technology. Here we turn toVertov and Mann as embodied expressions of this ocularcentrism.

Within Saukko's framework of the dialogic validity, both Vertov's and Mann's writing can be understood as emphatic expressions of their own lived realities, and a petition for others to share in their views. Rather than striving to express the lived realities of others-in adherence with Saukko's description of a dialogic validity - they remain concerned instead with the expression of their own realities since they each assume a privileged view. Both Vertov and Mann propose a combining of human and machine abilities to gain insight into the world around them. Vertov expressed this most adamantly in his vision of a "new, perfect man" constructed through the new machine technologies (17). Through the interaction of human and machine, the hybrid vision of the kino-eye becomes possible. ${ }^{3}$ His idea of the kino-eye was of a machine-eye, or camera-eye, which could achieve a better and clearer vision than the "naked eye" of human vision. In his writing, Vertov promotes the enhancement of the human vision through the machine, but also goes so far as to endow the camera-eye with its own voice. Vertov writes from this hybrid point of view, where the first person "I" is the voice of the kino-eye. As the kino-eye states, "I make the viewer see in the manner best suited to my presentation of this or that visual phenomenon." Vertov continues, "The eye submits to the will of the camera and is directed by it to those successive points of the action that, most succinctly and vividly, bring the film phrase to the height or depth of resolution" (16).

Steve Mann also proposes a combining of human and machine capabilities. Writing over eighty years after Vertov, Mann

3 Kino is the Russian word for cinema. 
is immersed in a world where language, theory, and science have actively engaged with the possibilities and struggles of the fusion of human and machine. Mann also speaks in the first person, but here the "I" refers to himself as a cyborg (cybernetic organism). Where Vertov's "cyborg" vision was more of a conceptual approach to the combining of human and machine, for Mann it has become a material synthesis. Mann states, "We are entering the post-human age. In this age, biology is no longer limited by the genetic codes of evolution" (2). For Mann personally this involves the constant mediation of experience through a WearComp, or wearable computer. The WearComp makes use of EyeTap technology as its input/output device. Mann also argues, "This [EyeTap] allows the user to view the world as images imprinted onto the retina by rays of laser light controlled through several linked computers. The WearComp user 'sees' through miniature cameras, with the image filtered into the computer system before finally being projected into the eye. . . In this way, eye and camera, mind and computer are joined" (9).

Through the fusion of human and machine, both Vertov and Mann engage with new ways of seeing the world. They both promote these new ways of seeing as liberating, a way of going beyond human limitations. As Vertov argues, "The position of our bodies while observing or our perception of a certain number of features of a visual phenomenon in a given instant are by no means obligatory limitations for the camera which, since it is perfected, perceives more and better" (15). For Vertov, the mechanical vision of the camera enables a means of seeing the world not just differently, but also more clearly: a perfection of human vision. Though Mann does not go so far as to speak of perfection in his writing, he does endorse his cyborg experience as a liberating one: "The wearable computer allows me to explore my humanity, alter my consciousness, shift my perceptions so that I can choose-at any given time- to see the world in very different, often quite liberating, ways" (3).

Beyond liberation from human limitation however, both Vertov and Mann write about their kino-eye/cyborg practice as a 
confrontation of a larger, limiting system. However, the defining features of these systems are quite different for their respective experiences. Vertov was writing just after the Russian Revolution of 1917, and his proposed new vision can be understood as one that confronted bourgeois values in favour of socialist revolution. Kinoeye provides a means of seeing through the deceptive regimes of bourgeois and religious domination. Vertov also speaks out strongly against the use of the camera to replicate human vision, and to continue to pacify and distract the masses with dramatic narrative films (13). Thus, Vertov promoted the revolutionary kino-eye vision as an active challenge to passive vision.

Mann also promotes his cyborg vision as a challenge to passivity. However, here it is a counter to the invisible yet ever more controlling nature of technology in twenty-first century society. For Mann, the challenge is a vast system of technology which commonly goes unnoticed and which "is everywhere, as ubiquitous as it is invisible, capable of changing the everyday minutiae of how we go about our lives, permeating our consciousness, altering fears, desires, and ways of being" (xi). Mann's writing about his cyborg experience articulates his attempt to insert some individual freedom and choice within this overarching system by confronting technology with technology (xii).

In this way, Mann's use of technology proposes a way of uncovering what tends to remain hidden, similar to the process of unveiling ideology. Whereas for Vertov, the power of the kino-eye was its difference from the myth of dominant ideals, for Mann the antidote to "blindness" is found in the aggressive use of the same apparatus against itself. However, both theorists, through their fusions with machines, bring to light normally unseen systems of domination, and promote their hybrid visions as means of counteraction.

Further, in echo of the ubiquitous nature of the deceptive systems, the new visions promoted by both Vertov and Mann are also always active and present. One of the powerful advantages these 
ever-present kino-eye and EyeTap visions have over "natural" human vision is the way in which they are able to organize the chaos of visual information in daily life. In this way, they help the human brain in the processing of information. For Vertov this is accomplished through skilful editing, which achieves clear results by cutting away "bothersome waste" and organizing the "chaos of visual events" (19). Likewise, Steve Mann's cyborg experience is also a process of editing out waste- the excess of information around him: "This freedom heightens my sensitivity to the flow of information that exists in a perpetual swirl all around us. It also allows me to, in effect, liberate my imaginative space from much of the visual detritus that confronts and distracts us in the form of billboards and flashing neon signs" (3).

In setting these two portions of writing in dialogue with each other, we can understand them not only as expressions of the theorists' own lived realities, but also emphatic imperatives driven by the desire to see more clearly. They are both concerned with liberation, but neither of them make use of technologies of vision that would fit Saukko's description of dialogic validity. Though they both focus their vision on "daily life," they are not concerned with capturing an expression of the lived experience of others. Rather, others must adopt Vertov's and Mann's mediated vision in order to insert their individual freedom into the normative system.

Contextual validity is concerned with locating the research within the wider social and political context as well as understand the research as an active participant in the shaping of that context. In this light, Vertov and Mann will be evaluated as products of their respective contexts, as well as reflexive participants.

Dziga Vertov (1896-1954) began making films at the outbreak of the Russian Revolution. Although there was a definite shortage of film stock in Russia at the time, Lenin valued the power of film to promote the communist message throughout the Soviet Union (Parkinson 72). By the early 1920s Vertov had begun writing about his theory of kino-eye, of which "Kinoks: A Revolution" is a part. He went on to put these theories into practice in the series 
of newsreels called Kino-Pravda, named after Lenin's newspaper Pravda, meaning "truth" (Thompson 203). These films were spread throughout Russia on "agit-prop" (agitation propaganda) trains and boats (Parkinson 72). Vertov went on to make feature length films as well, Man with a Movie Camera (1929) being his most widely acclaimed. Vertov worked vigorously to wake people up to revolutionary Marxist thought with his films. His raw material was filmed footage from everyday life, and his film editing style was constructed to parallel Marxist historical dialectics.

Steve Mann was born in Hamilton, Ontario in 1962, and is currently a professor at the University of Toronto in the department of Electrical and Computer Engineering. He has been experimenting with different wearable computer technologies since the late 1970s, and by now these technologies are lightweight and ever more sophisticated (Mann 6). In the glossary to Cyborg, Mann traces the term "cyborg" back to its first use in print in 1960 by Manfred E. Clynes and Nathan S. Kline who, while working on designing technologically sustained environments for astronauts at NASA, "imagined a human being that would merge unconsciously with technology" (Mann 261). Through to the 1980s, the term cyborg was limited primarily to the fields of science and military research. The term then made its way into science fiction, and was reinterpreted in popular culture through films such as The Terminator in 1984 (Whitley 8). Feminist theorist Donna Haraway, also gave new meaning to the term in her 1991 essay "A Cyborg Manifesto," which makes political use of the term: "The cyborg is our ontology; it gives us our politics" (150). Therefore, when Steve Mann names himself a cyborg at this point in time, he is conjuring up not only scientific, but also theoretical and popular associations. This may validate his message across a wide variety of disciplines, but is also cause for him to redefine the term once again as one who experiences a cyborg reality from the inside. For him the term cyborg is more about ontology than categorization, popular imagination, or metaphor (Mann 2). The concept of the cyborg is something he interprets from within. 
From his cyborg position, one of Mann's primary goals is to combat the pervasiveness of invisible technologies in current society. Mann grounds his description of these invisible technologies in Foucault's theory of the panopticon: "Today, Foucault's words seem not like cultural theory, but prophesy. The panopticon extends the power of itself, and we, the possibly observed, prefer to pretend that we retain our autonomy and privacy, in the face of all evidence to the contrary" (144). Mann describes how he uses his cyborg self to turn technology against itself in order to reassert acts of personal freedom and individual privacy. This is particularly realized in his confrontation of video surveillance in stores and public places, a major theme in his documentary Shooting Back (1997). In this way, Mann uses his cyborg experience as an act of resistance; however, his work must also be understood within a late capitalist context where the process of commodification articulates the capitalist project to produce exchange values (Mosco 140). Mann's EyeTap technology has been patented, along with several other inventions. ${ }^{4}$ Even the naming of his inventions with catchy names such as EyeTap and WearComp fits well with the pervasive marketing strategies of late capitalism. ${ }^{5}$

Thus, an evaluation of contextual validity reveals that both Vertov and Mann ground their experiments within a larger context, but reflexivity about their roles in those contexts is strategically limited. They both benefit from positions within powerful institutions: Vertov in the state film production unit, and Mann at the University of Toronto. Their messages are spread through mass communication networks: Vertov through the agit-prop trains, and Mann through global mass media and the internet. Key terms like kino-eye and EyeTap are also created to assist in the communication of their novel ideas. Vertov and Mann both also ground their

\footnotetext{
$4 \quad$ Canadian Intellectual Property patent CA 2248473.

5 The author assisted in the documentation of Mann's EyeTap technology. This was to be included in a proposal for the production of the EyeTap for the consumer market.
} 
arguments in a larger philosophical framework: Marx's dialectics and Foucault's panopticon. Both of their documentary film techniques involve reflexive use of their technologies in order to draw attention to different acts of seeing. Thus, both Vertov and Mann actively ground their work in their respective historical, political, and social contexts, but the overt and covert imperatives driving their work limit their reflexivity about their place in culture.

The process of unveiling that which remains covert formulates the evaluation criterion of the deconstructive validity: how well the research is able to unravel certain taken-for-granted truths. Vertov achieves this by challenging the norms of narrative cinema in both his writing and his films. He also reframes the commonly considered mistakes or accidents of cinematography (such as cranking the camera too fast or slow) as strengths of the kino-eye rather than human fault (Vertov 15). Mann too unravels the notion that surveillance only rests with large, powerful organizations, challenging this assumption from an individualized position. However, Vertov and Mann also take certain "truths" for granted. For example, in his editing practice, Vertov assumes that he has the authority to distinguish between "waste" and important content, and that he is able to recognize a more perfect view. When Steve Mann makes the assertion that the WearComp user is able to "instruct the computer to screen out all ads for cigarettes" (10), he is tapping into certain assumptions about the evil nature of both cigarettes and advertising. Both Vertov and Mann also take for granted a certain faith in new technologies.

The deconstructive validity also evaluates the binaries or hidden politics within the research. Vertov and Mann both achieve a certain amount of validity according to this criterion in the way they challenge the human/machine binary. This is achieved with Vertov's concept of the kino-eye, but also, for example, in the way he draws parallels between human and machine movements in Man with a Movie Camera. Mann takes this even further into the "post-human" era, where the biological definition of what is human is no longer 
sound. For Mann this is no longer a conceptual debate; his lived experience as a cyborg challenges this human/machine binary in a physical way. However, certain binaries also remain hidden within Vertov's and Mann's work. A striking example is demonstrated in the sight/blindness opposition each poses. Both Vertov and Mann attach their technologies to the sense of sight, and propose a means of seeing more clearly. This can be understood as part of the master metaphor of Western culture, driving the use of technology as well as methodological frameworks for theorizing about culture. The historical status of vision as the most dependable sense continues to give the study of vision weighty symbolic capital, and also promotes the desire to see more clearly. ${ }^{6}$ The bias toward sight in our language continues to shape our articulation of the world, and also filters our methods for understanding the world. Just as cultural theorists make use of complex methodological apparatuses, frequently articulated through metaphors of vision, to try to see the world more clearly; so Vertov and Mann implement physical, technological apparatuses to see the world more clearly. Even whithin a postmodern understanding where the possibility of an objective view has been abandoned, the desire to see, and power to see-even just a fragment-continues.

Thus, Paula Saukko's methodological approach of "combining methodologies" provides a means of seeing Dziga Vertov's and Steve Mann's work more clearly. Vertov's and Mann's works, as approaches to cultural research themselves, can also be understood as embodied extensions of the methodological practice of using a carefully constructed apparatus in order to see the world more clearly. Vertov and Mann shape the master metaphor of vision into a lived reality.

\section{Works Cited}

Foucault, Michel. Discipline and Punishment: The Birth of the Prision. Trans. Alan Sheridan. New York: Random House, 1979.

$6 \quad$ Again, see Downcast Eyes by Martin Jay. 


\section{DZIGA VERTOV AND STEVE MANN O Angela JoOSse}

Haraway, Donna. "A Cyborg Manifesto." Simians, Cyborgs, and Women: The Reinvention of Nature. New York: Routledge, 1991.

---. “The Promises of Monsters: A Regenerative Politics for Inappropriate/d Others." Cultural Studies. Eds. LawrenceGrossberg, Cary Nelson, Paula A. Treichler. New York:Routledge, 1992. 295-337.

Jay, Martin. Downcast Eyes: The Denigration of Vision in Twentieth-century French Thought. London: U ofCalifornia P, 1993.

Mann, Steve, with Hal Niedzviecki. Cyborg: Digital Destiny and Human Possibility in the Age of the Wearable Computer. Canada: Doubleday, 2001.

Mosco, Vincent. "Commodification." The Political Economy of Communication: Rethinking and Renewal. Thousand Oaks, CA: Sage Publications, 1996. 140-172.

Parkinson, David. History of Film. New York: Thames andHudson, 1995.

Saukko, Paula. Doing Research in Cultural Studies. London: Sage Publications, 2003.

Thompson, Kristen, and David Bordwell. Film History. New York: McGraw-Hill Inc., 1994.

Vertov, Dziga. Kino-Eye: The Writings of Dziga Vertov. Ed. Annette Michelson. Trans. Kevin O’Brien. London: U of California P, 1984.

Virilio, Paul. The Lost Dimension. Trans. Daniel Moshenberg. New York: Semiotext(e), 1991.

Whitley, Richard. The Intellectual and Social Organization of the Sciences. Oxford and New York: Oxford UP, 2000. 